\title{
EFEITOS DO ENDIVIDAMENTO EM MOEDA ESTRANGEIRA NO DESEMPENHO DAS EMPRESAS BRASILEIRAS
}

\author{
Guilherme Freitas Cardoso' \\ Guilherme Santos Souza ${ }^{2}$ \\ Vinícius Silva Pereira ${ }^{3}$
}

\begin{abstract}
Resumo: Esse trabalho buscou preencher a lacuna referente a estudos que avaliassem a utilização de recursos em moeda estrangeira por empresas brasileiras em relação ao desempenho, buscando entender se os benefícios auferidos por utilizar tais recursos superam os custos envolvidos na transação. Assim, este estudo objetiva analisar quais os efeitos do endividamento em moeda estrangeira das empresas brasileiras e, além disso, verificar se estas empresas ao se internacionalizarem auferem benefícios deste processo em relação ao seu desempenho. A partir de uma amostra composta por empresas brasileiras listadas na BM\&FBovespa no período de 2010 a 2016, utilizou-se de regressão com dados em painel para testar os efeitos do endividamento em moeda estrangeira no desempenho e, posteriormente, incluiu-se na análise o processo de internacionalização para verificar como este impactava na relação endividamento em moeda estrangeira e desempenho. Os resultados sugerem que a utilização de recursos provenientes do exterior apresenta relação estatisticamente significante com o desempenho e que as empresas que se utilizam destas ferramentas são menos suscetíveis a fatores cambiais do que as que não se utilizam, corroborando com a teoria Market Timing em que as empresas vão buscar oportunidades nas imperfeições do mercado. Ao se analisar os resultados referentes a interação entre o custo de endividamento das empresas internacionalizadas verifica-se a continuidade do alinhamento com a teoria Market Timing e, além disso, a relação dessas variáveis com o desempenho apresenta uma relação não monotônica, indicando a presença de pelo menos um ponto de inflexão na relação desempenho com a internacionalização.
\end{abstract}

Palavras-chave: Endividamento em moeda estrangeira; Desempenho; Internacionalização

guilhermefc05@gmail.com - Universidade Federal de Uberlândia

${ }^{2}$ guilhermessantos042@gmail.com - Universidade Federal de Uberlândia

${ }^{2}$ vinicius@fagen.ufu.br - Universidade Federal de Uberlândia

- DOI: http://dx.doi.org/10.14392/asaa.2018110202

- Artigo submetido em: 30/12/2017. Revisões requeridas em: 30/04/2018. Aceito em: 10/06/2018. 


\section{EFFECTS OF FOREIGN CURRENCY INDEBTEDNESS ON THE PERFORMANCE OF BRAZILIAN FIRMS}

Abstract: This paper sought to fill the gap regarding studies that evaluate the use of resources in foreign currency by Brazilian firms, whether these are multinationals or not, over the performance. Seeking to understand if the benefits obtained by using such resources outweigh the costs involved in the transaction. Thus, this paper aims to analyze the effects of the foreign currency debt of Brazilian companies and, in addition, to verify if these companies, when they are on the international markets, have benefits from this process over their performance. Based on a sample of Brazilian companies listed on the BM\&FBovespa from 2010 to 2016, panel data regression was used to test the effects of foreign currency indebtedness on performance and, subsequently, the process was included in the analysis of internationalization to verify how this had an impact on foreign currency indebtedness and performance. The results suggest that the use of resources in foreign currency is statistically related to performance and that companies that use these mechanisms are less susceptible to exchange rate factors than those that are not used, following the Market Timing theory in which companies seek for opportunities in market imperfections. When analyzing the results concerning the interaction between the cost of indebtedness of the internationalized companies, it was obtained the continuity of the alignment with the Market Timing theory and, in addition, the relation of these variables with the performance presents a non-monotonic relationship, indicating the presence of at least one inflection point in the relationship between performance and internationalization.

Keywords: Indebtedness foreign currency; Performance; Internationalization. 


\section{INTRODUÇÃO}

E stud studos sobre a estrutura de capital demonstram que as empresas selecionam como se financiar a partir de fatores de ordenamento (Pecking Order), de ponto ótimo (Trade-Off) e de oportunidades de mercado (Market Timing). Em busca de otimizar o desempenho por meio de fontes de financiamento menos dispendiosas, como o endividamento em moeda estrangeira, verifica-se um alinhamento com a teoria Market Timing. A qual aborda que as empresas vão explorar flutuações temporárias no custo de capital em relação a outras formas de recursos (Baker \& Wurgler, 2002).

Uma maior eficiência nos retornos está, geralmente, relacionada com estruturas de capital que apresentam uma maior alavancagem ou uma menor participação de capital próprio (Berger \& Di Patti, 2006). No entanto, devem ser considerados outros fatores que levam as empresas a buscarem recursos como as questões legais, expropriação de controle e propriedade, os conflitos de agência, assimetria de informações, oportunidades de mercado, dentre outros.

As empresas brasileiras possuem uma forte motivação para buscar financiamentos em outros países, pois conforme o Ranking Mundial de Juros Reais elaborado pela Moneyou e Management (2017), o Brasil ocupa o primeiro lugar em relação ao custo da dívida real, dentre quarenta nações avaliadas, com uma taxa ex ante (projeções médias de inflação futura) de 7,3\% ao ano. Contudo, caso utilize da estratégia de buscar recursos financeiros fora do país, a flutuação cambial pode expor as empresas brasileiras à riscos devido à inconstância do real frente ao dólar, e soma-se a essa questão o cenário político-econômico doméstico, gerando o questionamento se existe mesmo ganho nessa troca.

A globalização proporcionou às empresas brasileiras várias oportunidades nos aspectos estratégicos de seu negócio, abrindo as portas para que pudessem se internacionalizar e iniciar algum nível de relacionamento com outros países. Quando as empresas buscam investir no mercado estrangeiro, elas consideram, entre outras coisas, se tais processos serão lucrativos (Glaum \& Oesterle, 2007).

No entanto, auferir rentabilidade por meio da estratégia de internacionalização é complexo e não linear, sendo que estudos sobre internacionalização de empresas abordam o seu comportamento com o desempenho e os classificam em: positivo e linear (Tallman \& Li, 1996); negativo e linear (Geringer , Beamish \& DaCosta, 1989); em forma de U (Contractor, Kumar \& Kundu, 2007; Cunha, 2016; Lu \& Beamish, 2001); em forma de U invertido (Chen \& Hsu, 2010; Gomes \& Ramaswamy, 1999); e em formato de S horizontal (Contractor, Kundu \& Hsu, 2003; Riahi-Belkaoui, 1998).

No processo de busca por estruturas de capital menos dispendiosas, as empresas internacionalizadas podem auferir benefícios em relação ao custo de dívida quando se internacionalizam de forma patrimonial ou não patrimonial (Pereira \& Sheng, 2012), bem como ter mais acesso ao crédito por uma diminuição do risco sistemático e total de acordo com a situação econômica do país para o qual se internacionaliza (Kwok \& Reeb, 2000). Contudo, ainda não existem estudos analisando se os benefícios da utilização de recursos captados no exterior superam os custos e as oscilações do câmbio, afetando o custo da dívida e, consequentemente, o desempenho das empresas.

Neste contexto, alinhando-se com a teoria Market Timing em que as empresas buscam oportunidades nas imperfeições do mercado para captar recursos visando otimizar seu desempenho, o objetivo central deste estudo é verificar quais os efeitos do custo do endividamento em moeda estrangeira em relação à rentabilidade das empresas brasileiras, além de confrontar estas com empresas alavancadas apenas em moeda nacional. 
A estrutura de capital resultante do processo de internacionalização de acordo com a teoria Upstream-Downstream de Kwok e Reeb (2000) que demonstra que o risco e o acesso ao crédito alterna conforme o país de origem e de destino, de acordo com a situação econômica do país para o qual se internacionaliza. De forma semelhante no Brasil, o nível de endividamento das multinacionais brasileiras pode ser afetado de acordo com a escolha do país em que a empresa vai atuar, além disso, na média, as empresas brasileiras se expandem para países com economias mais estáveis (Ribeiro, 2014). A partir destes pressupostos, este estudo tem como objetivo secundário verificar se o processo de internacionalização impacta no custo do endividamento e, consequentemente, no desempenho de empresas internacionalizadas, devido as mesmas ou possuírem ativos fora do país ou auferirem receitas no exterior, tornando prováveis garantias no endividamento em instituições financeiras no exterior.

Ao analisar as teorias Market Timing e Upstream-Downstream cabe fazer as considerações que seguem: ao se internacionalizarem, empresas brasileiras teriam acesso mais facilitado às instituições financeiras do país de destino e consequentemente a recursos mais baratos, já que o Brasil é a economia com a maior taxa de juros da atualidade. Diversificando seu risco, por atuar em mercados menos adversos, a empresa passa a ter mais acesso a crédito já que seu risco total e sistemático, a partir das conclusões da teoria Upstream-Downstream, diminuem.

Nesse sentido é viável captar recursos em moeda estrangeira, levando em consideração outros fatores como o câmbio, por exemplo? A partir desse questionamento e do que foi exposto até agora, surgem às hipóteses apresentadas no referencial, sustentadas pelas respectivas teorias.

Este artigo encontra-se estruturado em cinco seções, considerando esta introdução. A segunda seção apresenta o referencial teórico para fundamentação bibliográfica e construção de hipóteses. A terceira descreve a metodologia, e na quarta são expostos e discutidos os resultados, e na última seção, são feitas as considerações finais do estudo.

\section{REFERENCIAL TEÓRICO}

Esta seção discute as teorias que envolvem a estrutura de capital e internacionalização e como os benefícios e custos relacionados ao endividamento em moeda estrangeira nas estruturas de capital se alinham com as decisões voltadas para a maximização do desempenho e como tais formas de recursos atuam nas empresas.

\subsection{Estrutura de capital e desempenho}

Estudos pioneiros referentes à estrutura de capital buscaram entender a sua relação com o desempenho. Durand (1952) evidenciou a existência de uma estrutura ótima de capital, no qual a harmonização das fontes de capital buscasse minimizar os custos referentes à captação de recursos. Já Modigliani e Miller (1958), demonstraram que a estrutura de capital é indiferente para o processo de financiamento das empresas, considerando mercados eficientes.

Estudos posteriores (Jensen \& Meckling, 1973; Myers, 1984) ampliaram tais constatações ao inserirem as imperfeições do mercado em suas análises, em que desencadearam em duas teorias, Pecking Order e Static Trade-Off. Segundo De Jong, Verbeek e Verwijmeren (2011), a diferença entre as duas teorias encontra-se no fato de que na Static Trade-Off a empresa aumenta sua alavancagem até atingir seu nível de endividamento alvo (ponto ótimo) e na teoria da Pecking Order o nível da dívida vai até atingir a capacidade de endividamento.

A teoria Trade-Off se baseia em economias fiscais relacionadas ao uso de dívidas e aos custos de falência e de agência esperados como custos de dificuldades financeiras. Já a teoria Pecking Order corresponde a uma hierarquia de preferências nos recursos internos e externos, com a preferência por 
recursos internos, devido à existência de assimetria de informação no mercado e custos de transação relevantes na colocação de títulos (Nakamura et al., 2007).

No entanto, estudos (Fama \& French, 1999; Graham \& Harvey, 2001) demonstram suporte limitado nas teorias Pecking Order e Static Trade-Off em buscar entender os aspectos referentes a estrutura de capital das empresas e não conseguiram verificar se tais teorias refletem o processo de captação de recursos ou se existem outros fatores negligenciados por ambas teorias.

Myers (1984) demonstra em seu estudo sobre os enigmas das estruturas de capital que as empresas se utilizam de momentos do mercado para efetuarem operações que aparentam ser vantajosas. Baker e Wurgler (2002) retomam esta ideia e retratam que a estrutura de capital é o resultado cumulativo das tentativas ao longo do tempo no mercado de capitais, desconsiderando a existência de uma estrutura ótima de capital.

Bolton, Chen e Wang (2013), aborda a presença de um comportamento dinâmico, pois as empresas buscam otimizar seus recursos de acordo com o mercado, em que mercados favoráveis representam uma oportunidade de obter benefícios decorrente deste cenário. Os mesmos autores retratam que estas implicações dinâmicas são finitas e devem servir para que as empresas consigam manter sua política de investimentos quase inalterada em momentos desfavoráveis.

No processo de avaliar as decisões de investimento deve se considerar os custos de financiamento e este conjunto de decisões, juntamente com a distribuição de resultados deve pautar como alocar o endividamento e o capital próprio (Perobelli \& Famá, 2003). Conforme Rossi Júnior (2007), empresas mais lucrativas e com maiores oportunidades de investimento mantêm uma razão mais alta de dívida em moeda estrangeira sobre a dívida total. Esse fato indica, provavelmente, que essas empresas respondem aos sinais apresentados pelo mercado e, assim, agem sobre estas imperfeiçoes para captar recursos, em alinhamento com a teoria de Market Timing na determinação da estrutura de capital.

Sendo assim, tomemos um caso hipotético para exemplificar a relação do endividamento em moeda estrangeira como forma de auferir benefícios para as empresas brasileiras que se utilizam deste mecanismo para obter menores custos de financiamento. No exemplo, baseando-se em duas empresas sediadas no Brasil que possuem as mesmas características, mas que se diferenciam, exclusivamente, na captação de recursos em moeda estrangeira. Assim, comparativamente pode-se afirmar a existência de diferenças entre os custos de captação das mesmas, sendo que devido a elevada taxa de juros no Brasil, as empresas que se endividam em moeda estrangeira podem se beneficiar em detrimento das que não se utilizam deste procedimento.

A partir destes pressupostos e com o intuito de contribuir com a teoria de Market Timing sobre os fatores de estrutura de capital e desempenho na ótica do endividamento em moeda estrangeira, sugere-se uma relação negativa do relacionamento entre o endividamento em moeda estrangeira $e$ o desempenho.

$\mathrm{H} 1$ : Empresas que utilizam de endividamento em moeda estrangeira possuem menor custo de dívida e, assim, melhor desempenho, em comparação a empresas que captam recursos financeiros apenas em instituições financeiras no mercado doméstico.

\subsection{Endividamento em empresas internacionalizadas}

1 A estratégia de internacionalização apresenta à empresa uma nova realidade, na qual ela precisa se adequar a um novo mercado. Segundo Sullivan (1994), estudos sobre internacionalização atribuem que estes processos ocorrem conforme o desempenho da multinacional, a sua estrutura, o modo de entrada e as atitudes da gestão sobre os ativos intangíveis. Neste processo as multinacionais auferem 
benefícios, como uma maior padronização de produtos, uma alocação mais eficiente de recursos e racionalização da produção (Kobrin, 1991) e com a economia de escala e escopo (Grant, 1987; Grant, Jammine \& Thomas, 1988).

Estudos sobre desempenho de multinacionais indicavam que o processo de internacionalização propiciava vantagens competitivas em níveis empresariais e retornos financeiros superiores, assim, indicando uma relação linear positiva. No entanto, outras pesquisas demonstraram que o processo de internacionalização pode implicar em aumento de riscos. Consequentemente, estudos identificaram a presença de relações não lineares na internacionalização devido a fatores macro e microeconômicos (Lin, Liu \& Chen, 2011).

No tocante da estrutura de capital, a internacionalização permite a redução dos riscos devido as multinacionais atuarem em mercados inversamente relacionados (Rugman, 1976). Hughes, Logue e Sweeney (1975) concluíram que a internacionalização gera um efeito positivo na estrutura de capital da empresa, ao confirmarem a visão de que os investidores percebem menores riscos de se investir numa multinacional, tendo como resultado um menor custo de capital, ou seja, uma estrutura de capital mais barata.

Em contraponto alguns estudos evidenciam um efeito negativo na relação entre internacionalização e estrutura de capital, sugerindo que atuar em mercado estrangeiro traz um aumento nos custos de agência, pois o investidor passa a lidar com diferenças impactantes como a língua nativa do país, diferença na estrutura dos ativos, alto custo de auditoria, por estar em outro país (Burgman, 1996; Lee \& Kwok, 1988) resultando em um aumento no risco total da empresa e em consequência uma diminuição na sua capacidade de endividamento.

Com relação ao comportamento da estrutura de capital no processo de internacionalização Kwok e Reeb (2000) propuseram uma teoria em relação à diferença de risco existente entre os países e o risco sistemático oriundo do país para o qual a empresa se internacionaliza. Nesse sentido eles concluíram que as empresas norte americanas que passavam a se envolver em operações internacionais tinham o seu risco total e sistemático uma tendência a aumentar, dificultando assim sua capacidade de endividamento (Upstream), em contrapartida empresas com base em mercados emergentes, ao se internacionalizarem para economias de países como os Estados Unidos tiveram uma diminuição no seu risco total e sistemático, possibilitando assim uma maior capacidade de endividamento (Downstream).

No Brasil, a internacionalização ganhou força principalmente na década de 90 com uma crescente expansão de empresas multinacionais buscando maiores mercados a fim de se manterem competitivas a nível mundial (Alem \& Cavalcanti, 2005). Conforme Saito e Hiramoto (2010), as multinacionais brasileiras se comportam de acordo com a teoria Upstream-Downstream no seu processo de internacionalização com a sua estrutura de capital, demonstrando uma relação positiva. Desta perspectiva, Pereira e Sheng (2012) e Ribeiro (2014) ampliam esse estudo ao considerarem fatores multidimensionais de internacionalização e os modos de entrada das multinacionais.

A literatura em finanças internacionais indica a possibilidade de que garantias (explícitas ou implícitas) do governo relacionadas ao regime cambial venham a viesar a política financeira das empresas para a direção de dívida denominada em moeda estrangeira (Rossi Júnior, 2007). Burnside, Eichembaum e Rebelo (1999) constroem um modelo no qual garantias implícitas induzem firmas e intermediários financeiros a tomar empréstimos em moeda estrangeira, mas sem se protegerem contra o risco cambial.

De modo similar ao exemplo hipotético referido no subtópico anterior, busca-se expandir o mesmo para exemplificar os prováveis benefícios que a estratégia de internacionalização pode causar na estrutura de capital em relação ao endividamento em moeda estrangeira. Assim, considerando duas empresas que possuem as mesmas características e ambas possuem endividamento em moeda estrangeira, mas uma delas realiza operações no cenário internacional, seja por meio patrimonial ou não. Comparativamente ambas empresas possuem diferentes custos do financiamento devido a pos- 
sibilidade das multinacionais se financiarem com taxas menores por possuírem garantias no cenário internacional pelo fato de atuarem no mercado estrangeiro e pela elevada taxa de juros no Brasil.

De forma a contribuir com a teoria Upstream-Downstream na qual as empresas internacionalizadas ao se inserirem nestes mercados por meio de investimentos e/ou receitas, podem utilizar mecanismos de captação de recursos em moeda estrangeira para auferir benefícios em que os mesmos fornecem as garantias neste processo de endividamento. Assim, pode-se sugerir que as empresas internacionalizadas possuem benefícios decorrentes do processo de internacionalização em relação a sua captação de recursos em moeda estrangeira.

$\mathrm{H} 2$ : Multinacionais que utilizam de endividamento em moeda estrangeira conseguem menores custo de financiamento, em relação às empresas domésticas que utilizam deste recurso, pois possuem ativos ou auferem receitas no exterior, e assim, melhor desempenho.

\section{METODOLOGIA}

Nesta seção serão abordados a amostra, a forma de coleta e tratamento dos dados, a definição das variáveis analisadas e os sinais esperados de acordo com a literatura e, por fim, os modelos regressivos de análise para este estudo.

\subsection{Amostra e coleta de dados}

Para a verificação da primeira hipótese os dados foram extraídos da base de dados Economática em bases trimestrais, visando melhor ajustamento em relação a volatilidade dos fatores cambiais, das empresas listadas na Bovespa nos períodos de 2010 a 2016. Este recorte temporal se apresenta devido às informações contábeis do endividamento em moeda estrangeira somente estarem disponíveis a partir do ano de 2010.

A amostra deste estudo delimita-se ao tratar a segunda hipótese, pois considera as empresas internacionalizadas e com isto foram acrescidos os relatórios do Ranking da Fundação Dom Cabral (FDC), em bases anuais, que classificam as multinacionais brasileiras de acordo com o grau de internacionalização, mantendo a base de dados e o recorte temporal inalterados.

Neste estudo foram desconsideradas as empresas financeiras devido as peculiaridades contábeis em relação às empresas não financeiras e os valores financeiros foram deflacionados pelo Índice de Preços Consumidor Amplo - (IPCA).

\subsection{Definição das variáveis}

Este artigo, bem como o modelo utilizado, baseia-se no estudo do Andrade e Galina (2013), sendo que acrescenta as variáveis do custo de capital de terceiros (KI) e do nível de endividamento em moeda estrangeira (DEME). Atribuindo o KI como variável explicativa do estudo, analisando sua relação no desempenho das empresas brasileiras (DES). Esta variável corresponde a razão entre as despesas financeiras e o endividamento.

A variável dependente do modelo, DES, será mensurada em relação ao retorno sobre os ativos (Return on Assets - ROA) das empresas brasileiras, assim como o utilizado em estudos anteriores na relação internacionalização-desempenho (Lu \& Beamish, 2004; Lin et al., 2011; Andrade \& Galina, 2013). $O$ índice mede a eficiência da empresa em relação as suas decisões de investimentos em ativos.

Foram adicionadas variáveis de controle, para garantir uma melhor ajustagem do modelo, a saber:

(a) o tamanho da empresa (LTAT): é utilizado como proxy para tamanho da empresa, o logaritmo do ativo, pois assim como analisado por Barcelos (2002), existe uma maior possibilidade para empresas de grande porte terem acesso a crédito. Em suma por essas empresas possuírem disponibilidade de 
garantias, maior transparência (principalmente quando se trata de empresas de capital aberto) bem como maior poder de barganha.

(b) o grau de internacionalização (DOI): foi utilizado o índice de transnacionalização, baseado na metodologia da UNCTAD - United Nations Conference on Trade and Development. De acordo com Sullivan (1994), o indicador multidimensional reduz o erro resultante da amostra, o erro sistemático e o viés aleatório. As informações do grau de internacionalização foram extraídas do Ranking FDC das Multinacionais Brasileiras elaborado pela Fundação Dom Cabral.

(c) endividamento em moeda estrangeira (DEME): montante de capital em dívidas realizadas fora do cenário nacional em instituições financeiras internacionais. Esta variável será tratada como dummy, em que para os dados referentes as empresas que não possuem endividamento em moeda estrangeira considera-se o valor 0 e para as que possuem o valor 1.

(d) câmbio (CAM): valor médio do câmbio entre os períodos analisados neste estudo em função da valorização ou desvalorização da moeda corrente em relação a outra moeda. Esta variável objetiva controlar os aspectos cambiais envolvidos no endividamento em moeda estrangeira que afetam o custo do endividamento e o desempenho.

As variáveis utilizadas neste estudo estão representadas no Quadro 1:

Quadro 1: Resumo das variáveis

\begin{tabular}{|c|c|c|c|c|}
\hline Variáveis & Sigla & Definição & Sinal Esperado & Estudo Base $^{a}$ \\
\hline \multicolumn{5}{|l|}{ Variável Explicativa } \\
\hline Custo do Endividamento & $\mathrm{KI}$ & Razão entre as despesas financeiras e o endividamento total & $(-)$ & \\
\hline \multicolumn{5}{|l|}{ Variável Dependente } \\
\hline Desempenho & DES & Lucro Líquido sobre ativo total (ROA) & & (1) (2) (3) \\
\hline \multicolumn{5}{|l|}{ Variável de Controle } \\
\hline Tamanho da empresa - Ativo Total & LTAT & Logaritmo natural do total de ativos da empresa & $(+)$ & (4) (5) \\
\hline Grau de Internacionalização & DOI & $\begin{array}{l}\text { Média aritmética de (ativos no exterior / ativos totais), } \\
\text { (receitas no exterior / receitas totais) e (funcionários no } \\
\text { exterior / funcionários) }\end{array}$ & $(-)(+)$ & (6) \\
\hline Câmbio & CAM & Valor médio do câmbio nos períodos & $(-)$ & \\
\hline $\begin{array}{l}\text { Endividamento em Moeda } \\
\text { estrangeira }\end{array}$ & DEME & $\begin{array}{l}\text { Relação binária entre empresas que possuem endividamento } \\
\text { em moeda estrangeira e as que não possuem }\end{array}$ & & \\
\hline Tipo de Indústria & SET & Dummies de Controle & & \\
\hline Período & PER & Dummies de Controle & & \\
\hline
\end{tabular}

Fonte: Elaborado pelos autores

\subsection{Modelo técnico de análise}

Os dados deste estudo serão tratados no software Stata e será utilizada a técnica de Regressão Múltipla com dados em painel. De acordo com Gujarati e Porter (2008), esta técnica analisa as variações das unidades transversais simultaneamente com as variações das unidades individuais ao longo do tempo.

Para verificar a primeira hipótese - empresas que utilizam de endividamento em moeda estrangeira possuem menor custo de dívida e, assim, melhor desempenho, em comparação a empresas que captam recursos financeiros apenas em instituições financeiras no mercado doméstico - foi definido o seguinte modelo que demostra a interação entre a dummy endividamento em moeda estrangeira com o custo do endividamento.

$$
\begin{gathered}
D E S i, t=\beta 0+(\beta 1+\delta 1 D E M E i, t) \\
K l i, t+\beta 2 \text { LTATi, t }+\beta 3 V C A M i, t+ \\
\text { (Modelo 1) }
\end{gathered}
$$

Para investigar a segunda hipótese - multinacionais que utilizam de endividamento em moeda estrangeira conseguem menores custo de financiamento e assim melhor desempenho, em relação as empresas domésticas que utilizam deste recurso, pois possuem ativos ou auferem receitas no exterior 
- foi utilizado o modelo regressivo que demostra a interação entre a dummy endividamento em moeda estrangeira com o custo do endividamento e o grau de internacionalização.

$D E S i, t=\beta 0+\beta 1 K l i, t+\beta 2 D O l i, t+\beta 3 D O I 2 i, t+\beta 4 D O I 3 i, t+(\beta 5+\delta 1$ DEMEi, $t) K l i, t * D O l i, t+(\beta 6+\delta 2 D E M E i, t) K l i, t * D O l i, t 2+(\beta 7+\delta 3 D E$

$$
\begin{gathered}
\text { MEi, } t) K l i, t^{*} D O l i, t 3+\beta 8 \text { LTATi, } t+\beta 9 C A M i, t+\sum_{n} S E T n \\
\text { (Modelo 2) }
\end{gathered}
$$

Para ambos os modelos regressivos serão realizados testes para verificar qual o melhor modelo a ser utilizado e também serão feitos testes para detectar e tratar a presença de outliers, multicolinearidade, heterocedasticidade e autocorrelação.

\section{RESULTADOS}

Esta seção aborda os resultados deste estudo demonstrando os efeitos do endividamento em moeda estrangeira em empresas brasileiras em relação aos seus pares que não se alavancam em moeda estrangeira. Por fim, verifica-se se o processo de internacionalização se apresenta como um fator que impacta a concessão de crédito, mais especificamente em moeda estrangeira, devido a presença de possíveis garantias das empresas que possuem ativos ou auferem receitas no exterior. Para análise dos dados deste estudo foram tratados possíveis dados extremos (outliers) com a utilização da técnica de winsorização (winsorizing) a 0,025.

\section{4 .1 Efeitos do endividamento em moeda estrangeira}

Antes de se analisar os resultados em si apresenta-se, na Tabela 1, a análise descritiva do estudo demonstrando a composição dos dados do modelo proposto, referente à quantidade de observações, média, desvio padrão, máximo e mínimo. É possível perceber que o desempenho médio é negativo de $-2 \%$ e o custo do endividamento médio é de $8 \%$.

Tabela 1: Análise Descritiva das Variáveis

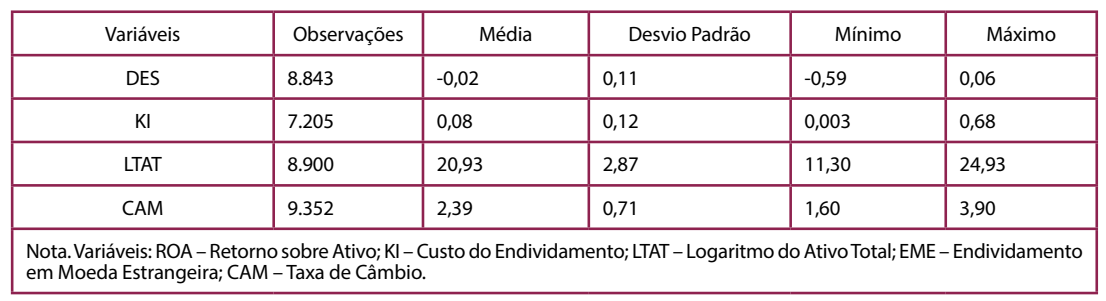

Fonte: Elaborado pelos autores

Ainda abordando os aspectos descritivos das variáveis, a Tabela 2 apresenta a matriz de correlação, na qual verifica-se que as variáveis independentes possuem baixas correlações entre si, o que corresponde um bom indicador de baixa endogeneidade e autocorrelação dos regressores.

Tabela 2: Matriz de Correlação das Variáveis

\begin{tabular}{|c|c|c|c|c|c|}
\hline & DES & KI & LTAT & CAM & DOI \\
\hline DES & 1,0000 & & & & \\
\hline KI & $-0,1586$ & 1,0000 & & & \\
\hline LTAT & 0,6443 & $-0,2827$ & 1,0000 & & \\
\hline CAM & $-0,0377$ & 0,1045 & $-0,0290$ & 1,0000 & 1,0000 \\
\hline DOI & $-0,3174$ & 0,0363 & 0,1696 & 0,1821 & \\
\hline \multicolumn{7}{|l|}{ Nota. Variáveis: DES - Retorno sobre o Ativo; KI-Custo do Endividamento; LTAT - Logaritmo do Ativo Total; EME-Endividamento } \\
\hline
\end{tabular}

Fonte: Elaborado pelos autores 
Na sequência foi testada a primeira hipótese que aborda os efeitos do endividamento em moeda estrangeira na estrutura de capital das empresas não financeiras brasileiras e, consequentemente, no desempenho. Foram realizados testes (Breusch-Pagan, Chow e Hausman) para verificar o método de regressão que melhor se ajustaria para o modelo definido, a partir destes testes foi determinado o modelo de efeitos fixos, e com isto não foram controlados os aspectos do setor.

Para detectar possíveis problemas de multicolinearidade no modelo regressivo foi realizado o teste VIF (Variance Inflation Factor) em que o maior valor VIF dos regressores não fosse superior a 10. Constatou-se a presença de multicolinearidade entre a variável câmbio e a dummy de controle para o período na amostra de empresas que não possuem endividamento em moeda estrangeira. Após a realização de testes com essas variáveis definiu-se a não utilização da dummy de controle do período para essas empresas.

Tabela 3: Resultados Estimados (Modelo 1)

\begin{tabular}{|c|c|c|}
\hline \multirow{2}{*}{ Variáveis } & \multicolumn{2}{|c|}{ DES - Retorno sobre o ativo } \\
\hline & CDME & SDME \\
\hline Constante & $-0,1170$ & $-0,6636^{* *}$ \\
\hline DEME*KI & $-0,1663^{* * *}$ & $-0,0640$ \\
\hline LTAT & 0,0064 & $0.0320^{* *}$ \\
\hline CAM & -0.0027 & $-0,0019$ \\
\hline Observações & 2.548 & 2.305 \\
\hline Dummy Período & Sim & Não \\
\hline $\mathrm{R}^{2}$ Ajustado & 0,096 & 0,050 \\
\hline \multicolumn{3}{|c|}{$\begin{array}{l}\text { Nota. Os asteriscos**,** } \mathrm{e}^{* * *} \text { representam, respectivamente, estatísticas significantes ao nível de } 10 \%, 5 \% \text { e } 1 \% \text {. } \\
\text { Variáveis: CDME: Emprasas que possuem Endividamento em Moeda Estrangeira; SDME: Empresas que não possuem Endividamento } \\
\text { em Moeda Estrangeira; DES - Retorno sobre o Ativo; DEME*KI - Interação dummy endividamento em moeda estrangeira com o custo } \\
\text { do endividamento; LTAT - Logaritmo do Ativo Total; CAM - Taxa de Câmbio. }\end{array}$} \\
\hline
\end{tabular}

Fonte: Elaborado pelos autores

A Tabela 3 demonstra a interação entre as variáveis custo do endividamento (KI) e a dummy endividamento em moeda estrangeira (DEME). Destarte, corrobora-se a primeira hipótese, empresas que utilizam de endividamento em moeda estrangeira possuem menor custo de dívida e, assim, melhor desempenho em relação a seus pares que buscam se endividar apenas no mercado doméstico. Tal constatação deve-se a existência de significância estatística na interação entre custo do financiamento e possuir endividamento em moeda estrangeria com o desempenho. Infere-se assim um alinhamento com a teoria Market Timing, ao demonstrar que as empresas buscam oportunidades nas imperfeições do mercado, neste caso se endividar em moeda estrangeira.

A variável de controle tamanho da empresa apresentou significância apenas para empresas que não possuem endividamento em moeda estrangeira, bem como uma relação positiva. Esta situação corrobora com a teoria de que empresas maiores teriam disponibilidade de garantias e maior poder de barganha, conseguindo com isso melhores custos de financiamento e melhor retorno, quando buscam recursos no mercado doméstico, o que não se mostrou significante para empresas com dívida em moeda estrangeira.

Em contrapartida, no caso para as empresas que buscaram recursos em moeda estrangeira a interação com o custo da dívida em relação ao desempenho se mostrou significativa enquanto que o tamanho da empresa não, podendo inferir que é mais vantajoso para a empresa utilizar recursos em moeda estrangeira do que se valer de seus ativos como garantia e buscar recursos no mercado interno.

\subsection{Endividamento em moeda estrangeira nas empresas internacionalizadas}

Após a análise dos efeitos do endividamento em moeda estrangeira para as empresas brasileiras este estudo busca verificar se o processo de internacionalização afeta a relação entre o custo do endividamento e o desempenho. Pelo fato das multinacionais possuírem ativos ou auferirem receitas no 
exterior, sendo estas prováveis garantias para a concessão de crédito em instituições financeiras fora do Brasil, e teriam maiores benefícios em relação as empresas que atuam, somente, no mercado local. Conforme apresentado na metodologia os dados referentes ao modelo regressivo foi delimitado devido o parâmetro de internacionalização utilizado encontrar-se em bases anuais.

A Tabela 4 mostra os resultados referente a segunda hipótese, empresas que utilizam endividamento em moeda estrangeira e são internacionalizadas possuem menores custo de financiamento e, assim, melhor desempenho. Destarte, ratifica-se a segunda hipótese ao demonstrar que empresas internacionalizadas que possuem endividamento em moeda estrangeira apresentam menores custos de financiamento em relação a seus pares que atuam apenas no mercado doméstico e também utilizam recursos em moeda estrangeira, conforme demonstrado pela relação negativa e significativa no custo do endividamento com o desempenho. Tais resultados corroboram com a teoria Upstream-Downstream, e com os estudos de Ribeiro (2014) e Saito e Hiramoto (2010) que constataram que, na média, as empresas brasileiras se internacionalizam para economias menos adversas diminuindo o risco e com isto aumentam seu endividamento.

Tabela 4: Resultados Estimados (Modelo 2)

\begin{tabular}{|c|c|c|}
\hline \multirow{2}{*}{ Variáveis } & \multicolumn{2}{|c|}{ DES - Retorno sobre o ativo } \\
\hline & Internacionalizadas & Não Internacionalizadas \\
\hline Constante & 0,7952 & 0,0294 \\
\hline $\mathrm{KI}$ & $-1,0773^{* *}$ & $-0,0673$ \\
\hline DOI & $-2,9771^{* * *}$ & \\
\hline DOI2 & $13,8741^{* * *}$ & \\
\hline DOI3 & $-16,8218^{* * *}$ & \\
\hline DEME*KI*DOI & $18,4090^{* * *}$ & \\
\hline DEME*KI* ${ }^{*} I^{2}$ & $-84,6945^{* * *}$ & \\
\hline $\mathrm{DEME}^{*} \mathrm{KI}^{*} \mathrm{DOI}^{3}$ & $99,4809^{* * *}$ & \\
\hline LTAT & $-0,0226$ & 0,0038 \\
\hline CAM & $-0,0135$ & $-0,0289^{* *}$ \\
\hline Observações & 82 & 627 \\
\hline Dummy Período & Sim & Sim \\
\hline $\mathrm{R}^{2}$ Ajustado & 0,478 & 0,0828 \\
\hline $\begin{array}{l}\text { Nota. Os asteriscos }{ }^{*},{ }^{* *} \mathrm{e}^{* * *} \\
\text { Variáveis: } \mathrm{DES}-\text { Retorno sobre } \\
=1 \text { ) com o custo do endividan }\end{array}$ & $\begin{array}{l}\text { mente, estatísticas sig } \\
\text { Interação apenas empr } \\
\text { internacionalização; LT }\end{array}$ & $\begin{array}{l}10 \%, 5 \% \text { e } 1 \% \text {. } \\
\text { ento em moeda estrangeir } \\
\text { tivo Total; CAM - Taxa de }\end{array}$ \\
\hline
\end{tabular}

Também infere-se a existência de uma relação em forma de S horizontal devido a presença de sinais significantes e opostos em cada um dos respectivos coeficientes lineares e não lineares, corroborando com os estudos de Contractor et al. (2003) e Riahi-Belkaoui (1998). Assim, indicando que menores níveis de internacionalização (DOI) tem uma relação negativa com o desempenho. Já quando o grau de internacionalização (DOI2) aumenta apresenta-se uma relação positiva com o desempenho. No entanto, estes benefícios decorrentes do aumento da internacionalização no desempenho não se confirmam para as multinacionais que apresentam um alto grau de internacionalização (DOI3) devido a existência de uma relação negativa com o desempenho. Tais resultados indicam prováveis conflitos de agência decorrentes da assimetria de informações nos distintos momentos da internacionalização das empresas estudadas.

Ao se analisar os resultados referentes a interação entre o custo de endividamento das empresas internacionalizadas verifica-se a continuidade dos resultados obtidos anteriormente, a significância estatística e o formato de S horizontal, assim, corroborando com as teorias do Market Timing e Upstream-Downstream. Contudo, os sinais encontrados se invertem devido a interação das variáveis. Assim, 
empresas com menor nível de internacionalização apresentam uma relação positiva entre o custo do endividamento e o desempenho. Ao se aumentar o nível de internacionalização esta relação se torna negativa e quando com alto nível de internacionalização esta relação retorna a ser positiva. Portanto, corroborando com a segunda hipótese que as empresas internacionalizadas se utilizam do processo de internacionalização para obterem benefícios na captação de recursos no exterior.

A variável de controle tamanho do ativo para as empresas internacionalizadas apresenta sinal inverso do encontrado no Modelo 1, indicando uma relação negativa entre o tamanho e o desempenho, demonstrando que quanto maior for a empresa menor o seu desempenho. Para a variável de controle câmbio verifica-se a manutenção da relação negativa com o desempenho. No entanto, verifica-se a presença de significância estatística nas empresas não internacionalizadas, assim, sugere-se que estas empresas não realizam procedimentos para se protegerem das variações cambiais, diferentemente das internacionalizadas e, com isto, estando suscetíveis as variações cambiais que afetam negativamente o seu desempenho.

\subsection{Checagem de robustez}

Com o objetivo de checar a robustez empírica e teórica dos resultados encontrados, foram realizadas as mesmas análises utilizando outras variáveis tanto dependentes quanto para controle. Nesse sentido foram utilizadas variáveis mencionadas nos trabalhos de Andrade e Galina (2013) como medidas de desempenho que avaliam as empresas por outra perspectiva, como pelo valor (ROE e Q de Tobin) e também pelas vendas (ROS), e as variáveis, sugeridas como de controle, por Riahi-Belkaoui (1998) em seu trabalho, pioneiro em encontrar uma relação não monotônica entre internacionalização e desempenho, são elas: medida de intensidade de ativos fixos e oportunidades de crescimento.

As Tabelas 5 e 6 (ver Apêndice) demonstram os resultados relacionados a primeira hipótese deste estudo em que compara o desempenho das empresas que possuem ou não endividamento em moeda estrangeira. A checagem de robustez relacionada a inclusão de outras variáveis de controle como sugerido por Riahi-Belkaoui (1998), demonstra os mesmos resultados relacionados as variáveis explicativas deste estudo em que as empresas que possuem endividamento em moeda estrangeira apresentam uma relação negativa significativa com o desempenho, em alinhamento com o resultado encontrado neste estudo e ratificando a teoria Market Timing na qual as empresas buscam oportunidades nas imperfeiçoes do mercado.

Ao se considerar medidas de desempenho relacionados a criação de valor (ROE e Q de Tobin) conforme abordado por Andrade e Galina (2013) e demonstrado na Tabela 6 (ver Apêndice), verifica-se que os resultados relacionados a variável explicativa não apresentam significância em relação ao ROE. Já em relação ao Q de Tobin existe significância tanto para as que possuem endividamento em moeda estrangeira quanto as que não possuem, sendo que para as que não tem endividamento em moeda estrangeira há maior poder de explicação.

Os resultados evidenciados pela checagem de robustez para o modelo 1 podem ser analisados a partir dos conflitos de agência, pois quando se avalia o desempenho por medidas de rentabilidade relacionadas a maximização dos resultados da empresa (ROA e ROS) se analisa os dados pela perspectiva dos gestores. Já quando se avalia o desempenho pela ótica da maximização do valor para os acionistas (ROE e Q de Tobin), verifica-se que os impactos do endividamento em moeda estrangeira refletem efeitos distintos dos encontrados quando se avalia pela maximização dos resultados da empresa.

Os resultados da análise da segunda hipótese, Tabelas 7 e 8 (ver Apêndice), ao se incluir as variáveis de controle sugeridas no trabalho de Riahi-Belkaoui (1998), corroboram com aqueles obtidos neste estudo em relação ao custo do endividamento. No entanto, ao se analisar o processo de internacio- 
nalização não são encontrados os mesmos resultados e verifica-se, somente, que um alto nível de internacionalização $\left(\mathrm{DOl}^{3}\right)$ apresenta relação significante negativa com o desempenho.

Já ao substituir a variável dependente pela proxy $Q$ de Tobin o resultado se mostra contrário ao obtido neste estudo, na qual as empresas que possuem endividamento em moeda estrangeira e não são internacionalizadas apresentam relação significativa com o desempenho, este mensurado pelo $Q$ de Tobin. É possível justificar os resultados obtidos com a inclusão da variável Q de Tobin, pela análise da metodologia utilizada para realizar o seu cálculo, na qual são somadas o valor das ações (ordinárias e preferenciais) com as dívidas da empresa e esse valor é dividido pelo ativo total. Nesse sentido, quanto maior o valor do $Q$ de Tobin maior o deslocamento do valor da empresa em relação ao seu valor contábil, concluindo assim que em relação ao desempenho de mercado a valorização da empresa não tem significância.

\section{CONSIDERAÇÕES FINAIS}

Esse trabalho buscou preencher a lacuna referente a estudos que analisassem a utilização de recursos em moeda estrangeira por empresas brasileiras, sendo estas internacionalizadas ou não, em relação ao desempenho dessas empresas buscando entender se os benefícios auferidos por utilizar tais recursos superam os custos envolvidos na transação. Adicionalmente, busca-se contribuir com as teorias relacionadas as decisões de estrutura de capital e de internacionalização.

Os resultados sugerem um alinhamento com a teoria Market Timing, ao demonstrar que as empresas buscam oportunidades nas imperfeições do mercado, como se endividar em moeda estrangeira. Ao se analisar os resultados referentes a interação entre o custo de endividamento das empresas internacionalizadas verifica-se a continuidade do alinhamento com a teoria Market Timing e, além disso, a relação dessas variáveis com o desempenho apresenta um formato de $\mathrm{S}$ horizontal, indicando a presença de dois pontos de inflexão na relação desempenho com a internacionalização, e estas também quando interagidas com o endividamento em moeda estrangeira.

Para este estudo foram realizados testes de robustez considerando limitações de outros estudos (Andrade \& Galina, 2013; Riahi-Belkaoui, 1998). Os resultados sugerem a existência de conflitos de agencia entre gestores e acionistas, ao se verificar que a utilização do endividamento em moeda estrangeira apresenta relação significativa ao se analisar pela perspectiva dos gestores e não significante em relação aos acionistas.

No sentido desses resultados cabe a sugestão para trabalhos futuros de aprofundar a análise na medida de desempenho em relação ao valor, buscando explorar o porquê da inversão de resultados nas variáveis explicativas e de controle, quando analisado o desempenho por medidas de rentabilidade e de valor. As limitações deste estudo encontram-se em relação aos dados das empresas internacionalizadas que se encontram em bases anuais e também que estas empresas apresentam comparativamente uma amostragem menor do que as não internacionalizadas.

REFERÊNCIAS

Alem, A. C., \& Cavalcanti, C. E. (2005). O BNDES e o apoio à internacionalização das empresas brasileiras: algumas reflexões. Revista do BNDES, 12(24), 43-76.

Andrade, A. M. F., \& Galina, S. V. R. (2013). Efeitos da Internacionalização sobre o desempenho de multinacionais de economias em desenvolvimento. Revista de Administração Contemporânea, 17(2), 239-262.

Baker, M., \& Wurgler, J. (2002). Market timing and capital structure. The Journal of Finance, 57(1), 1-32. 
Barcelos, L. C. (2002). Determinantes do acesso ao crédito empresarial no Brasil: teoria e evidências empíricas (Doctoral dissertation, Universidade de São Paulo).

Berger, A. N., \& Di Patti, E. B. (2006). Capital structure and firm performance: A new approach to testing agency theory and an application to the banking industry. Journal of Banking \& Finance, 30(4), 10651102.

Bolton, P., Chen, H., \& Wang, N. (2013). Market timing, investment, and risk management. Journal of Financial Economics, 109(1), 40-62.

Burgman, T. A. (1996). An empirical examination of multinational corporate capital structure. Journal of International Business Studies, 27(3), 553-570.

Burnside, C., Eichenbaum, M., \& Rebelo, S. (1999). Hedging and financial fragilities in fixed exchange rate regimes (No. 461). University of Rochester-Center for Economic Research.

Chen, H., \& Hsu, C. W. (2010). Internationalization, resource allocation and firm performance. Industrial Marketing Management, 39(7), 1103-1110.

Contractor, F. J., Kundu, S. K., \& Hsu, C. C. (2003). A three-stage theory of international expansion: The link between multinationality and performance in the service sector. Journal of International Business Studies, 34(1), 5-18.

Contractor, F. J., Kumar, V., \& Kundu, S. K. (2007). Nature of the relationship between international expansion and performance: The case of emerging market firms. Journal of World Business, 42(4), 401-417.

Cunha, P. F. D. (2016). A relação entre a internacionalização e o desempenho econômico de empresas brasileiras de capital aberto. Dissertação de mestrado, Universidade Federal de Uberlândia, Uberlândia, MG, Brasil.

De Jong, A., Verbeek, M., \& Verwijmeren, P. (2011). Firms' debt-equity decisions when the static tradeoff theory and the pecking order theory disagree. Journal of Banking \& Finance, 35(5), 1303-1314.

Durand, D. (1952). Costs of debt and equity funds for business: trends and problems of measurement. In Conference on research in business finance (pp. 215-262). NBER.

Fama, E. F., \& French, K. R. (1999). The corporate cost of capital and the return on corporate investment. The Journal of Finance, 54(6), 1939-1967.

Geringer, M. J., Beamish, P. W., \& DaCosta, R. C. (1989). Diversification strategy and internationalization: Implications for MNE performance. Strategic Management Journal, 10(2), 109-119.

Glaum, M., \& Oesterle, M. J. (2007). 40 years of research on internationalization and firm performance: more questions than answers?. Management International Review, 47(3), 307-317.

Graham, J. R., \& Harvey, C. R. (2001). The theory and practice of corporate finance: Evidence from the field. Journal of Financial Economics, 60(2), 187-243.

Grant, R. M. (1987). Multinationality and performance among British manufacturing companies. Journal of International Business Studies, 18(3), 79-89.

Grant, R. M., Jammine, A. P., \&Thomas, H. (1988). Diversity, diversification, and profitability among British manufacturing companies, 1972-1984. Academy of Management Journal, 31(4), 771-801.

Gomes, L., \& Ramaswamy, K. (1999). An empirical examination of the form of the relationship between multinationality and performance. Journal of International Business Studies, 173-187.

Gujarati, D. N., \& Porter, D. C. (2008). Econometria Básica. McGraw-Hill Companies, Inc., New York, NY, EUA. 
Hughes, J. S., Logue, D. E., \& Sweeney, R. J. (1975). Corporate international diversification and market assigned measures of risk and diversification. Journal of Financial and Quantitative Analysis, 10(4), 627-637.

Jensen, M., \& Meckling, W. (1976) Theory of the firm: Managerial behavior, agency costs, and ownership structure. Journal of Financial Economics, 3, 305-360.

Jensen, M. C. (1989). Active investors, LBOs, and the privatization of bankruptcy. Journal of Applied Corporate Finance, 2 (1), 35-44.

Kobrin, S. J. (1991). An empirical analysis of the determinants of global integration. Strategic Management Journal, 12(S1), 17-31.

Kwok, C. C., \& Reeb, D. M. (2000). Internationalization and firm risk: An upstream-downstream hypothesis. Journal of International Business Studies, 31(4), 611-629.

Lee, K. C., \& Kwok, C. C. (1988). Multinational corporations vs. domestic corporations: International environmental factors and determinants of capital structure. Journal of International Business Studies, 19(2), 195-217.

Lin, W. T., Liu, Y., \& Cheng, K. Y. (2011). The internationalization and performance of a firm: Moderating effect of a firm's behavior. Journal of International Management, 17(1), 83-95.

Lu, J. W., \& Beamish, P. W. (2001). The internationalization and performance of SMEs. Strategic Management Journal, 22(6-7), 565-586.

Modigliani, F., \& Miller, M. H. (1958). The cost of capital, corporation finance and the theory of investment. The American Economic Review, 261-297.

Moneyou, \& Management (2017), Infinity Asset. Ranking Mundial de Juros Reais: Fevereiro 2017. 2017. Recuperado em 04 abril, 2017, de http://moneyou.com.br/wp-content/uploads/2017/02/rankingdejurosreais210217.pdf.

Myers, S. C. (1984). The capital structure puzzle. The Journal of Finance, 39(3), 574-592.

Nakamura, W. T., Martin, D. M. L., Forte, D., de Carvalho Filho, A. F., da Costa, A. C. F., \& do Amaral, A. C. (2007). Determinantes de estrutura de capital no mercado brasileiro: análise de regressão com painel de dados no período 1999-2003. Revista Contabilidade \& Finanças, 18(44), 72-85.

Pereira, V. S., \& Sheng, H. (2012). H. Os efeitos dos modos de entrada sobre o endividamento das multinacionais. In XII Encontro Brasileiro de Finanças.

Perobelli, F. F. C., \& Famá, R. (2003). Fatores determinantes da estrutura de capital para empresas latino-americanas. Revista de Administração Contemporânea, 7(1), 9-35.

Riahi-Belkaoui, A. (1998). The effects of the degree of internationalization on firm performance. International Business Review, 7(3), 315-321.

Ribeiro, R. B. (2014). Estrutura de capital e internacionalização de empresas brasileiras: uma análise da hipótese Upstream-downstream. Dissertação de mestrado, Universidade Federal de Uberlândia, Uberlândia, MG, Brasil.

Rossi Júnior, J. L. (2007). O endividamento das empresas em moeda estrangeira e o regime cambial. Pesquisa e Planejamento Econômico. 37(1), 1-20.

Rugman, A. M. (1976). Risk reduction by international diversification. Journal of International Business Studies, 75-80.

Saito, R., \& Hiramoto, E. (2010). Foreign activity effects and capital structure: Brazilian evidence. Academia. Revista Latinoamericana de Administración, (45). 
Sullivan, D. (1994). Measuring the degree of internationalization of a firm. Journal of International Business Studies, 25(2), 325-342.

Tallman, S., \& Li, J. (1996). Effects of international diversity and product diversity on the performance of multinational firms. Academy of Management Journal, 39(1), 179-196.

\section{APÊNDICE}

Tabela 5: Resultados Estimados - Medidas de Desempenho (Gestores)

\begin{tabular}{|c|c|c|c|c|c|c|c|c|}
\hline \multirow{3}{*}{ Variáveis } & \multicolumn{4}{|c|}{ ROA } & \multicolumn{4}{|c|}{ ROS } \\
\hline & \multicolumn{2}{|c|}{ CDME } & \multicolumn{2}{|c|}{ SDME } & \multicolumn{2}{|c|}{ CDME } & \multicolumn{2}{|c|}{ SDME } \\
\hline & $-0,117$ & 0,000 & $-0,6636^{* *}$ & $-0,114^{* *}$ & 0,000 & 0,000 & $-1,598^{* * *}$ & $-1,381^{* * *}$ \\
\hline DEME*KI & $-0,166^{* * *}$ & $-0,161^{* * *}$ & $-0,0640$ & $-0,046$ & $-1,403^{* * *}$ & $-1,371^{* * *}$ & $-0,185$ & $-0,263^{* *}$ \\
\hline LTAT & 0,006 & $0,005^{* * *}$ & $0,0320^{* *}$ & $0,006^{* * *}$ & $0,053^{* * *}$ & $0,062^{* * *}$ & $0,084^{* * *}$ & $0,073^{* * *}$ \\
\hline CAM & $-0,003$ & $-0,035^{* * *}$ & $-0,0019$ & $-0,003$ & $-0,333^{* * *}$ & $-0,397^{* * *}$ & $-0,102^{* * *}$ & $-0,087^{* * *}$ \\
\hline CRESC & & $0,022^{* * *}$ & & $0,032^{* * *}$ & & $0,247^{* * *}$ & & $0,310^{* * *}$ \\
\hline IAF & & $-0,006$ & & $-0,011$ & & $-0,084$ & & $-0,108$ \\
\hline Observações & 2.548 & 2.522 & 2.548 & 2.161 & 2.529 & 2.186 & 2.520 & 2.152 \\
\hline Dummy Período & \multicolumn{2}{|c|}{ Sim } & \multicolumn{2}{|c|}{ Não } & \multicolumn{2}{|c|}{ Sim } & \multicolumn{2}{|c|}{ Não } \\
\hline $\mathrm{R}^{2}$ Ajustado & 0,096 & 0,1858 & 0,050 & 0,0592 & 0,0979 & 0,1140 & 0,0175 & 0,0313 \\
\hline \multicolumn{9}{|c|}{$\begin{array}{l}\text { Nota. Os asteriscos * }{ }^{* *} \mathrm{e}^{* * *} \text { representam, respectivamente, estatísticas significantes ao nível de } 10 \%, 5 \% \text { e } 1 \% \text {. } \\
\text { Variáveis: CDME: Empresas que possuem Endividamento em Moeda Estrangeira; SDME: Empresas que não possuem Endividamento em } \\
\text { Moeda Estrangeira; DES - Retorno sobre o Ativo; DEME*KI - Interação dummy endividamento em moeda estrangeira com o custo do } \\
\text { endividamento; LTAT - Logaritmo do Ativo Total; CAM - Taxa de Câmbio; CRESC - Oportunidades de Crescimento; IAF - Intensidade dos } \\
\text { Ativos Fixos. }\end{array}$} \\
\hline
\end{tabular}

\section{Fonte: Elaborado pelos autores}

Tabela 6: Resultados Estimados - Medidas de Desempenho (Acionistas)

\begin{tabular}{|c|c|c|c|c|c|c|c|c|}
\hline \multirow{3}{*}{ Variáveis } & \multicolumn{4}{|c|}{ ROE } & \multicolumn{4}{|c|}{ Q de Tobin } \\
\hline & \multicolumn{2}{|c|}{ CDME } & \multicolumn{2}{|c|}{ SDME } & \multicolumn{2}{|c|}{ CDME } & \multicolumn{2}{|c|}{ SDME } \\
\hline & 0,000 & $0,960^{* *}$ & 0,043 & 0,251 & $5,329^{* * *}$ & $6,079^{* * *}$ & $17,922^{* * *}$ & $15,437^{* * *}$ \\
\hline DEME*KI & 0,002 & $-0,099$ & 0,035 & 0,026 & $-0,241^{* *}$ & $-0,250^{* *}$ & $-0,730^{* * *}$ & $-0,809 * * *$ \\
\hline LTAT & 0,004 & $-0,042^{* *}$ & 0,0001 & $-0,009$ & $-0,187^{* * *}$ & $-0,224^{* * *}$ & $-0,763^{* * *}$ & $-0,652^{* * *}$ \\
\hline CAM & $-0,020$ & $-0,005$ & $-0,016^{* * *}$ & $-0,013^{* *}$ & $-0,086^{* * *}$ & $-0,088^{* * *}$ & $-0,246^{* * *}$ & $-0,228^{* * *}$ \\
\hline CRESC & & 0,028 & & $0,041^{* * *}$ & & $-0,0258$ & & $-0,001$ \\
\hline IAF & & 0,019 & & $-0,080$ & & $0,2154^{*}$ & & $0,628^{* * *}$ \\
\hline Observações & 2.529 & 2.186 & 2.520 & 2.152 & 2.238 & 2.224 & 1.826 & 1.754 \\
\hline Dummy Período & \multicolumn{2}{|c|}{ Sim } & \multicolumn{2}{|c|}{ Não } & \multicolumn{2}{|c|}{ Sim } & \multicolumn{2}{|c|}{ Não } \\
\hline $\mathrm{R}^{2}$ Ajustado & 0,0152 & 0,0002 & 0,0098 & 0,0051 & 0,093 & 0,100 & 0,287 & 0,211 \\
\hline \multicolumn{9}{|c|}{$\begin{array}{l}\text { Nota. Os asteriscos *,** } \mathrm{e}^{* * *} \text { representam, respectivamente, estatísticas significantes ao nível de } 10 \%, 5 \% \text { e } 1 \% \text {. } \\
\text { Variáveis: CDME: Empresas que possuem Endividamento em Moeda Estrangeira; SDME: Empresas que não possuem Endividamento em } \\
\text { Moeda Estrangeira; DES - Retorno sobre o Ativo; DEME*KI - Interação dummy endividamento em moeda estrangeira com o custo do } \\
\text { endividamento; LTAT - Logaritmo do Ativo Total; CAM - Taxa de Câmbio; CRESC - Oportunidades de Crescimento; IAF - Intensidade dos } \\
\text { Ativos Fixos. }\end{array}$} \\
\hline
\end{tabular}

Fonte: Elaborado pelos autores 
Tabela 7: Resultados Estimados - Medidas de Desempenho (Gestores)

\begin{tabular}{|c|c|c|c|c|c|c|c|c|}
\hline \multirow{2}{*}{ Variáveis } & \multicolumn{4}{|c|}{ ROA } & \multicolumn{3}{c|}{ ROS } \\
\cline { 2 - 9 } & \multicolumn{2}{|c|}{ INT NINT } & \multicolumn{2}{c|}{ INT } & \multicolumn{2}{c|}{ NINT } \\
\hline Constante & 0,795 & 0,181 & 0,029 & $-0,329^{*}$ & $-0,233$ & $-0,334$ & $-0,494$ & $-0,238$ \\
\hline KI & $-1,077^{* *}$ & $-0,346^{*}$ & $-0,067$ & $-0,086^{* *}$ & $-0,149$ & $-0,234$ & $-0,301^{*}$ & $-0,278$ \\
\hline DOI & $-2,977^{* * *}$ & $-1,309$ & & & $-0,843$ & $-1,261$ & & \\
\hline DOI2 & $13,874^{* * *}$ & 6,777 & & & 5,314 & 7,048 & & \\
\hline DOI3 & $-16,822^{* * *}$ & $-8,233^{*}$ & & & $-6,751$ & $-8,457$ & & \\
\hline DEME*KI*DOI & $18,409^{* * *}$ & 8,432 & & & 4,492 & 6,823 & & \\
\hline DEME*KI*DOI ${ }^{2}$ & $-84,695^{* * *}$ & $-45,606^{* *}$ & & & $-34,256$ & $-44,670$ & & \\
\hline DEME*KI*DOI & $99,481^{* * *}$ & $54,944^{* *}$ & & & 43,529 & 54,745 & & \\
\hline LTAT & $-0,023$ & $-0,002$ & 0,004 & $0,018^{* *}$ & 0,016 & 0,021 & 0,028 & 0,014 \\
\hline CAM & $-0,014$ & $-0,006$ & $-0,029^{* *}$ & $-0,009$ & $-0,013$ & 0,001 & 0,003 & 0,032 \\
\hline CRESC & & 0,029 & & $0,102^{* * *}$ & & 0,010 & & $0,363^{* * *}$ \\
\hline IAF & & $-0,070$ & & $-0,033$ & & $-0,140$ & \\
\hline Observações & 82 & 73 & 627 & 537 & 82 & 73 & 624 & 537 \\
\hline Dummy Período & Sim & Sim & Sim & Sim & Sim & Sim & Sim & Sim \\
\hline R' Ajustado & 0,478 & 0,2933 & 0,0828 & 0,2152 & 0,3829 & 0,3825 & 0,0952 & 0,1339 \\
\hline
\end{tabular}

Nota. Os asteriscos ${ }^{*},{ }^{* *} \mathrm{e}{ }^{* * *}$ representam, respectivamente, estatísticas significantes ao nível de $10 \%, 5 \%$ e $1 \%$.

Variáveis: INT - Internacionalizadas com endividamento em moeda estrangeira; NINT - Não Internacionalizadas coom endividamento em moeda estrangeira; DES - Retorno sobre o Ativo; DEME*KI*DOI - Interação apenas empresas com endividamento em moeda estrangeir (dummy = 1) com o custo do endividamento e com o grau de internacionalização; LTAT - Logaritmo do Ativo Total; CAM - Taxa de Câmbio; CRESC - Oportunidades de Crescimento; IAF - Intensidade dos Ativos Fixos.

\section{Fonte: Elaborado pelos autores}

Tabela 8: Resultados Estimados - Medidas de Desempenho (Acionistas)

\begin{tabular}{|c|c|c|c|c|c|c|c|c|}
\hline \multirow{3}{*}{$\begin{array}{l}\text { Variáveis } \\
\text { Constante }\end{array}$} & \multicolumn{4}{|c|}{ ROE } & \multicolumn{4}{|c|}{ Q de Tobin } \\
\hline & \multicolumn{2}{|c|}{ INT } & \multicolumn{2}{|c|}{ NINT } & \multicolumn{2}{|c|}{ INT } & \multicolumn{2}{|c|}{ NINT } \\
\hline & 0,237 & 0,635 & $-0,494^{*}$ & $-0,608^{* *}$ & $4,546^{* * *}$ & $4,220^{*}$ & $3,272^{* * *}$ & $2,599^{* * *}$ \\
\hline $\mathrm{KI}$ & $-0,394$ & $-0,895$ & $-0,067$ & $-0,084$ & 0,567 & 0,940 & $-0,135^{* *}$ & $-0,155^{* *}$ \\
\hline DOI & $-1,481$ & $-3,282$ & & & 1,816 & 3,585 & & \\
\hline $\mathrm{DOI} 2$ & 0,918 & 8,238 & & & $-10,131$ & $-15,132$ & & \\
\hline DOI3 & 3,230 & $-4,309$ & & & 11,417 & 15,176 & & \\
\hline $\mathrm{KI}{ }^{*} \mathrm{DOI}$ & 5,720 & 19,856 & & & $-13,280$ & $-19,945$ & & \\
\hline $\mathrm{KI}^{*} \mathrm{DOI}^{2}$ & 5,690 & $-52,454$ & & & 60,191 & 79,775 & & \\
\hline $\mathrm{KI}^{*} \mathrm{DOl}^{3}$ & $-34,000$ & 26,938 & & & $-70,401$ & $-85,164$ & & \\
\hline LTAT & $-0,001$ & $-0,003$ & $0,033^{* * *}$ & $0,033^{* *}$ & $-0,146^{* *}$ & $-0,152^{*}$ & $-0,092^{* * *}$ & $-0,067^{* *}$ \\
\hline CAM & $-0,003$ & $-0,070$ & $-0,055$ & $-0,013$ & $-0,094$ & 0,014 & $-0,110^{* * *}$ & $-0,087^{* * *}$ \\
\hline CRESC & & 0,112 & & 0,062 & & 0,062 & & 0,020 \\
\hline IAF & & $-0,274^{* *}$ & & 0,030 & & $0,421^{*}$ & & 0,048 \\
\hline Observações & 82 & 73 & 627 & 537 & 81 & 72 & 539 & 466 \\
\hline Dummy Período & Sim & Sim & Sim & Sim & Sim & Sim & Sim & Sim \\
\hline $\mathrm{R}^{2}$ Ajustado & 0,1132 & 0,1648 & 0,0257 & 0,0254 & 0,1675 & 0,1473 & 0,0001 & 0,0023 \\
\hline \multicolumn{9}{|c|}{$\begin{array}{l}\text { Nota. Os asteriscos }{ }^{*},{ }^{* *} \mathrm{e}^{* * *} \text { representam, respectivamente, estatísticas significantes ao nível de } 10 \%, 5 \% \text { e } 1 \% \text {. } \\
\text { Variáveis: INT - Internacionalizadas com endividamento em moeda estrangeira; NINT - Não Internacionalizadas com endividamento em } \\
\text { moeda estrangeira; DES - Retorno sobre o Ativo; DEME*KI*DOI - Interação apenas empresas com endividamento em moeda estrangeira } \\
\text { (dummy = 1) com o custo do endividamento e com o grau de internacionalização; LTAT - Logaritmo do Ativo Total; CAM - Taxa de Câmbio; } \\
\text { CRESC - Oportunidades de Crescimento;IAF - Intensidade dos Ativos Fixos. }\end{array}$} \\
\hline
\end{tabular}

Fonte: Elaborado pelos autores 